\title{
Turbulent Kinetic Energy Dissipation in Barrow Canyon
}

\author{
E. L. SHROYER* \\ Woods Hole Oceanographic Institution, Woods Hole, Massachusetts
}

(Manuscript received 12 October 2011, in final form 10 January 2012)

\begin{abstract}
Pacific Water flows across the shallow Chukchi Sea before reaching the Arctic Ocean, where it is a source of heat, freshwater, nutrients, and carbon. A substantial portion of Pacific Water is routed through Barrow Canyon, located in the northeast corner of the Chukchi. Barrow Canyon is a region of complex geometry and forcing where a variety of water masses have been observed to coexist. These factors contribute to a dynamic physical environment, with the potential for significant water mass transformation. The measurements of turbulent kinetic energy dissipation presented here indicate diapycnal mixing is important in the upper canyon. Elevated dissipation rates were observed near the pycnocline, effectively mixing winter and summer water masses, as well as within the bottom boundary layer. The slopes of shear/stratification layers, combined with analysis of rotary spectra, suggest that near-inertial wave activity may be important in modulating dissipation near the bottom. Because the canyon is known to be a hotspot of productivity with an active benthic community, mixing may be an important factor in maintenance of the biological environment.
\end{abstract}

\section{Introduction}

The signature of Pacific Water is clearly evident in the hydrographic structure of the deep Arctic (e.g., Aagaard et al. 1981; Toole et al. 2011), where it is a source of heat, freshwater, carbon, and nutrients (Coachman et al. 1975; Walsh et al. 1989; Woodgate and Aagaard 2005). However, before reaching the deep Arctic, Pacific Water must make its way through the Bering Strait and across the shallow $(\sim 40 \mathrm{~m})$ Chukchi Sea. Physical processes including air-sea interactions, ice-sea interactions, and vertical mixing can influence the character of the $\mathrm{Pa}$ cific Water as it transverses the Chukchi. Water mass transformations that happen en route potentially impact how and where subsurface water in the deep Arctic is ventilated.

Pacific Water flowing into the Chukchi Sea is modulated by a strong seasonal cycle, which along the eastern side of the Bering Strait is characterized by the presence

\footnotetext{
* Current affiliation: College of Earth, Ocean, and Atmospheric Sciences, Oregon State University, Corvallis, Oregon.

Corresponding author address: Emily Shroyer, College of Earth, Ocean, and Atmospheric Sciences, Oregon State University, 104 CEOAS Administration Building, Corvallis, OR 97331.

E-mail: eshroyer@coas.oregonstate.edu
}

of warm, fresh Alaskan Coastal Water (ACW) in summer and well-mixed, cold Bering Winter Water (BWW) in the winter. After passing through the Bering Strait, a significant portion of the Pacific Water is topographically steered along the coast of Alaska before entering the Arctic Ocean through Barrow Canyon at the northeast corner of the Chukchi Sea (e.g., Weingartner et al. 2005). Barrow Canyon stretches across the Beaufort slope toward the northeast with an along-canyon scale of $\sim 200 \mathrm{~km}$, cross-canyon scale of $\sim 50 \mathrm{~km}$, and depth exceeding $250 \mathrm{~m}$ (Fig. 1). As with submarine canyons found throughout the World Ocean, Barrow Canyon has been highlighted as a region of enhanced across-shelf exchange (Weingartner et al. 1998; Allen and Durrieu de Madron 2009; Watanabe 2011).

Observations have shown that both summer and winter water masses may occupy Barrow Canyon at the same time during summer months, with ACW typically located along the shoreward flank or near the surface and BWW found at depth (e.g., Pickart et al. 2005). Not all Pacific Water follows the Alaskan coast, and the coexistence of summer and winter water in Barrow Canyon may be related to the multiple pathways available for Pacific Water flowing through the Chukchi (black arrows in Fig. 1). In particular, water following either the western pathway through Herald Canyon or the central channel (Weingartner et al. 2005) may be steered through the 


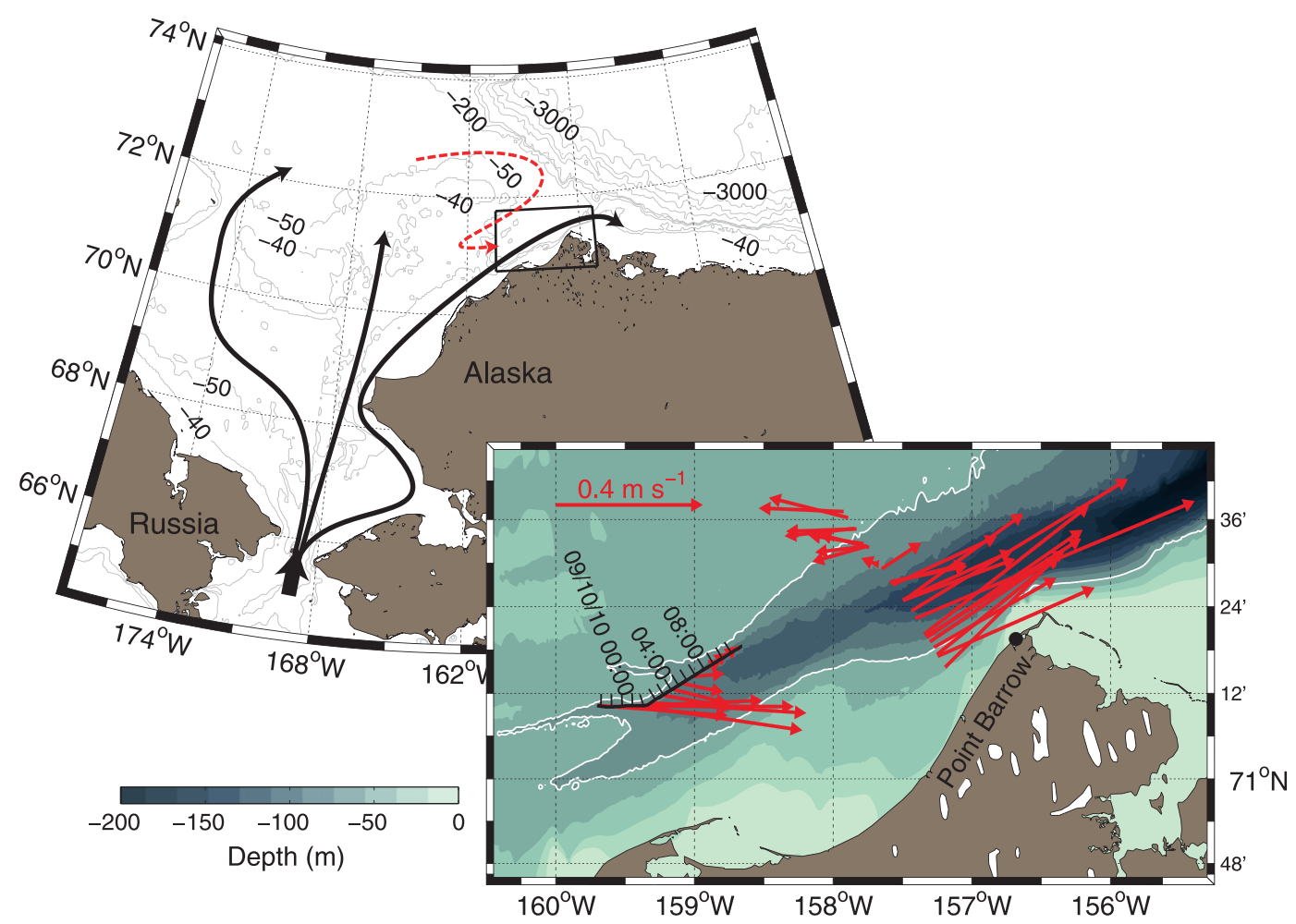

FIG. 1. (top) Chukchi Sea and Alaskan Beaufort shelf with the three primary pathways of Pacific Water schematically indicated by black arrows. The red dashed arrow represents the retroflection of western branches into the canyon. (bottom) Multibeam bathymetry for Barrow Canyon. The 70-m isobath is contoured in white. The microstructure transect line (black) with corresponding depth-averaged velocity vectors (red) is apparent near the head of the canyon. Velocity vectors from a cross-canyon ADCP line, which was made 2 days prior to turbulence survey, are also shown.

head of Barrow Canyon after turning southward around Hanna Shoal (red dashed arrow in Fig. 1), as suggested by previous modeling efforts (Winsor and Chapman 2004; Spall 2007). Recent multibeam bathymetry data (Fig. 1, bottom) reveal several side channels that extend up onto the Chukchi Shelf from the head of the canyon, allowing for drainage of water from different sources. For example, ACW flowing rapidly along the Alaskan coast may "catch up" to slower-moving BWW that traveled along a western pathway in Barrow Canyon.

$\mathrm{BWW}$ is both saltier and colder than $\mathrm{ACW}$; furthermore, BWW from the western Chukchi tends to be nutrient rich compared to either that from the eastern Chukchi or ACW (e.g., Walsh et al. 1989). ${ }^{1}$ The confluence of these different water masses in Barrow Canyon creates the potential for transformation via

\footnotetext{
${ }^{1}$ My use of BWW encompasses both Bering Shelf Water and Anadyr Water. A more thorough description of water masses in this region may be found in Coachman et al. (1975) or Weingartner et al. (2005).
}

physical processes, such as across-shelf exchange and mixing. As mentioned above, consequent changes to the hydrographic and current structure may have implications downstream to current stability and ventilation of the deep Arctic basin; these processes may be particularly important considering the potential for Barrow Canyon to enhance exchange between the Chukchi and Beaufort Seas. In addition, physical control of nutrient exchange may have an impact upon Barrow Canyon's ecosystem, which is characterized by elevated primary production and an active benthic community (e.g., Grebmeier et al. 2006).

Although the general circulation pattern described above is useful for large-scale context, it is important to note that variability exists. Barrow Canyon is a dynamic region, and circulation therein is influenced by a variety of processes, including wind-driven current reversals (e.g., Woodgate et al. 2005; Weingartner et al. 2009), topographic shelf waves (Aagaard and Roach 1990; Signorini et al. 1997), hydraulic control (Pickart et al. 2005), and internal wave activity (as noted in this work). Because of its scientific richness and relative accessibility 
by Arctic standards, Barrow Canyon has been a focus of many prior studies that typically have involved shipboard conductivity-temperature-depth/acoustic Doppler current profiler (CTD/ADCP) surveys and limited mooring deployments. Here, data are presented from the first microstructure measurements of temperature, salinity, and shear made in Barrow Canyon. These data show elevated turbulent kinetic energy (TKE) dissipation around the pycnocline, where summer and winter water masses directly mix, and in the bottom boundary layer, where mixing may be important to the benthic community.

To date, only a handful of other direct measurements of turbulent mixing have been made in the Arctic. Observations from the deep Arctic indicate a quiescent environment with weak TKE dissipation $\left(\sim 10^{-9} \mathrm{~W} \mathrm{~kg}^{-1}\right.$ ) (e.g., Padman and Dillon 1991; Lenn et al. 2009). As with low latitudes, mixing tends to be largest near rough topography and in shallow waters (D'Asaro and Morison 1992; Sundfjord et al. 2008; Rainville and Winsor 2008). For example, Rainville and Winsor (2008) estimate TKE dissipation rates near $10^{-5} \mathrm{~W} \mathrm{~kg}^{-1}$, a value that is similar to peak rates measured here, over the Beaufort shelf using temperature microstructure. In the eastern Arctic, elevated dissipation rates (reaching values of $10^{-5} \mathrm{~W} \mathrm{~kg}^{-1}$ ) were observed near the interface of dense plume water descending through the Faroe Bank Channel (FBC) (Fer et al. 2010). Despite differences (e.g., spatial scales, bottom-attached versus intermediate exit depths of plumes, etc.), parallels between the FBC overflow and BWW flowing through Barrow Canyon may be drawn: namely, both consider dense water flowing through topographic restrictions. The data presented here are similar to those presented by Fer et al. (2010) in that they suggest strong, yet variable mixing along the interface as well as elevated mixing within the bottom boundary layer.

\section{Measurements}

A $\sim 45-\mathrm{km}$-long microstructure transect was conducted over a 16-h period on 9-10 September 2010 (Fig. 1), as an opportunistic component of an in-depth CTD/ADCP survey of the Alaskan/Canadian Beaufort shelf and slope onboard USCGC Healy. Approximately 250 profiles of high-frequency shear, temperature variance, and CTD data were collected using a Rockland Scientific Vertical Microstructure Profiler (VMP-2000). The transect line was chosen primarily for logistical reasons, since turbulence measurements were ancillary to the main measurement effort. The transect was mapped between the deployment locations of two moorings; because of the placement of one mooring, the profiling transect was made down one of the side branches at the head of the canyon before turning parallel to the primary axis of the canyon. The transect was made off center of the primary axis to avoid the strongest down-canyon currents, which would tend to advect the loosely tethered profiler under the vessel. A prior cross-canyon ADCP transect, made just downstream of the microstructure transect, measured near-surface velocities in excess of $1 \mathrm{~m} \mathrm{~s}^{-1}$ (Fig. 1), and the transect line was chosen to fall outside these rapidly moving waters.

The VMP-2000 was equipped with a Seabird CTD sensor for standard measurements of temperature, salinity, and depth. Temporal resolution between profiles was roughly $4 \mathrm{~min}$; profiles extended from $\sim 2 \mathrm{~m}$ beneath the surface to $\sim 10 \mathrm{~m}$ above the bottom. The VMP-2000 fell at roughly a constant rate $\left(\sim 0.8 \mathrm{~m} \mathrm{~s}^{-1}\right)$ through the water column. CTD data were acquired at $64 \mathrm{~Hz}$, and data were averaged into 1-m bins during processing. Temperature data shown herein are from the Seabird system as opposed to the microstructure sensors (FP07). In addition to VMP measurements, a Teledyne RDI 150-kHz ADCP provided water-column velocity data along the transect line. The ADCP measured from $\sim 20-\mathrm{m}$ depth to $\sim 10 \mathrm{~m}$ above the bottom in 4-m bins. ADCP data were averaged into 1-min bins to reduce noise.

Microstructure shear (sampled at $512 \mathrm{~Hz}$ ) was used to estimate the TKE dissipation rate $\epsilon=7.5 \nu \overline{(\partial u / \partial z)^{2}}$ over $1-\mathrm{m}$ vertical bins using the shear variance $\overline{(\partial u / \partial z)^{2}}$ and the molecular viscosity of seawater $\nu$. The VMP-2000 was equipped with two shear probes; these records were flagged for outliers before being averaged together. Further details of calculating $\epsilon$ from loosely tethered profilers may be found in Moum et al. (1995) and Lueck et al. (2002). The noise floor of the VMP-2000 is estimated as $\epsilon \approx 10^{-10} \mathrm{~W} \mathrm{~kg}^{-1}$. From $\epsilon$ and the buoyancy frequency $N$ (calculated from CTD data), an effective turbulent viscosity $K_{\rho}$ can be determined using $K_{\rho}=$ $\Gamma \epsilon / N^{2}$, where $\Gamma=0.2$ is the assumed mixing efficiency (Osborn 1980).

This is one of the first times that a loosely tethered profiler has been operated from an icebreaker in the coastal Pacific Arctic. Fortunately, the cruise occurred during calm weather with little ice cover, and the measurements, which depend critically upon the profiler falling freely through the water column, were made without much difficulty. Because of the size of the icebreaker, it is estimated that dissipation measurements were contaminated by the ship's wake in the upper $10 \mathrm{~m}$, slightly deeper than that expected from a smaller vessel. Therefore, values of $\epsilon$ above $10 \mathrm{~m}$ were discarded. 

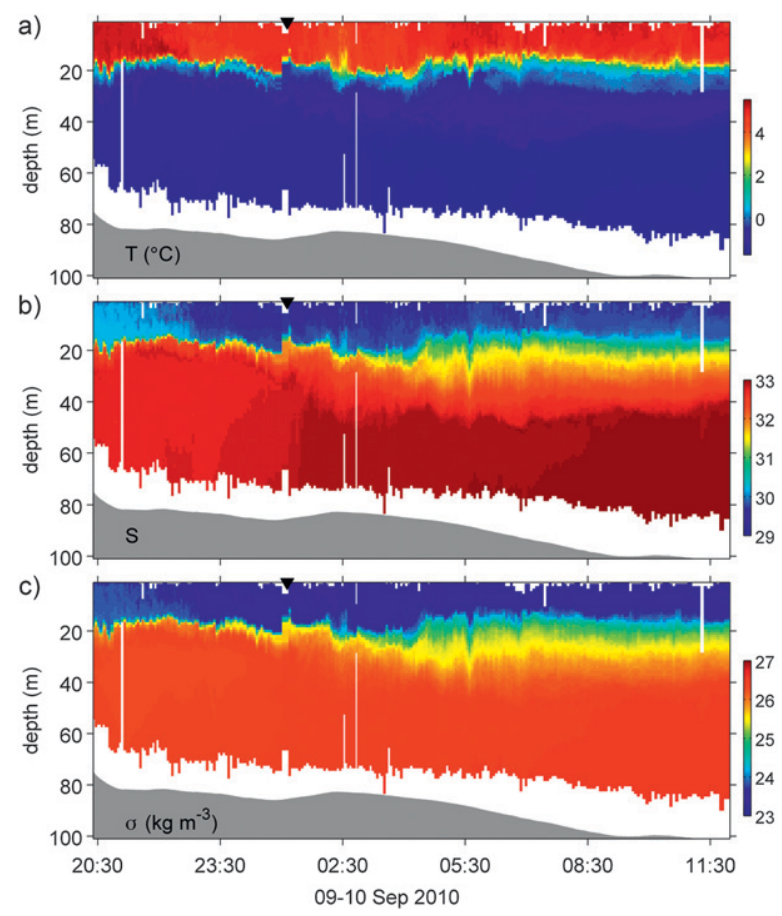

FIG. 2. (a) Temperature, (b) salinity, (c) potential density, (d) eastward perturbation velocity, (e) eastward depth-averaged velocity, (f) northward perturbation velocity, and (g) northward depth-averaged velocity measured along the microstructure transect mapped in Fig. 1. Black markers near the top of the panels indicate the time when the ship turned toward the northeast.

\section{Observations}

In general, near-surface temperature $T$ (Fig. 2a) and salinity $S$ (Fig. 2b) were relatively warm and fresh, consistent with that expected for ACW. At depth, water was cool and salty with $T \sim-1^{\circ} \mathrm{C}$ and $S \sim 32.5$. A slight increase/decrease in $S / T$ is observed at depth moving down transect. The $T-S$ properties of the coldest, saltiest water are consistent with those of BWW. A clear shift was observed in the potential density structure $\sigma_{\theta}$ (Fig. 2c), in which the pycnocline width increased moving down transect. This shift occurred sometime after the ship turned toward the northeast and is likely related to the position of the ship in relation to the coastal current. Previous observations (e.g., Signorini et al. 1997; Pickart et al. 2005) have noted a wedge-shaped pycnocline (i.e., one that is more diffuse along the outer bank) that would produce this effect.

For presentation purposes, the velocity was divided into depth-averaged $(U, V)$ and perturbation $\left(u^{\prime}, v^{\prime}\right)$ components (Figs. $2 \mathrm{~d}-\mathrm{g}$ ). Note that the average was taken over resolved depths from roughly $20 \mathrm{~m}$ beneath the surface to $10 \mathrm{~m}$ above the bottom. Data were not extrapolated outside this region. The perturbation velocity is the difference between the total velocity and the depth average. Initially, the velocity was dominated by the zonal component (Fig. 2e), flowing down the side
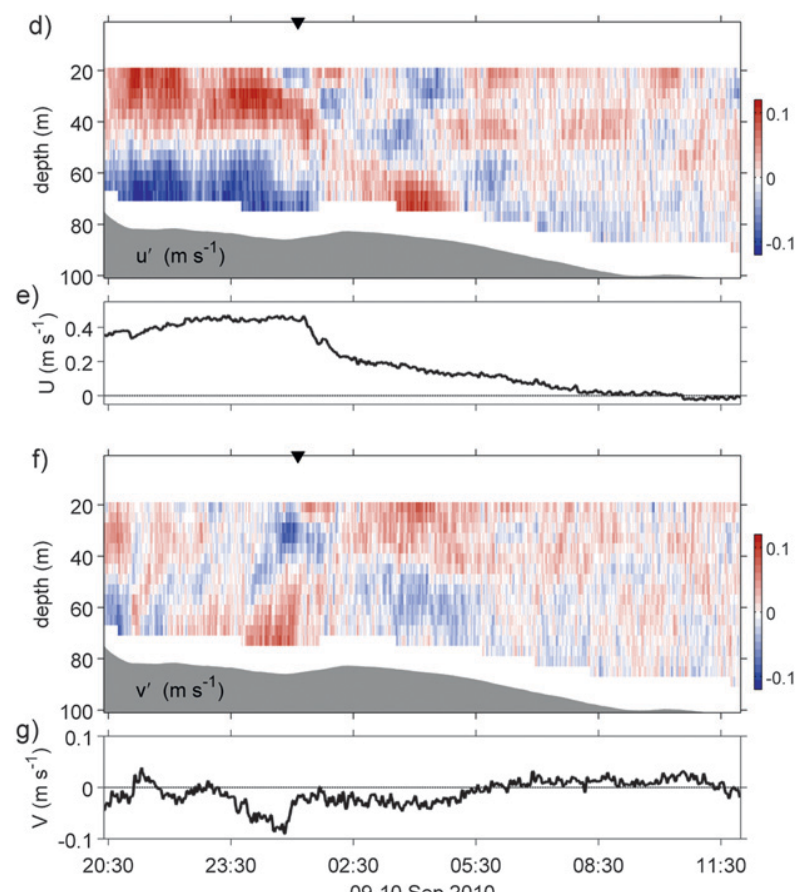

09-10 Sep 2010 branch at the head of the canyon roughly aligned with the transect path. In this region, $U$ exceeded $0.4 \mathrm{~m} \mathrm{~s}^{-1}$. The strongest eastward velocities were located in the upper part of the water column (Fig. 2d). The depthaveraged meridional component $V$ fluctuated around zero with a maximum magnitude of less than $0.1 \mathrm{~m} \mathrm{~s}^{-1}$ (Fig. 2g). However, the perturbation velocity $v^{\prime}$ was of a similar magnitude to $u^{\prime}$ (Fig. 2f). Farther down transect, the ship was positioned on the periphery of the current, and the speed was reduced significantly (Figs. 1, 2d-g).

As suggested previously, the stratification $N^{2}$ (Fig. 3a) about the pycnocline became weaker and more diffuse moving down transect. The transition may have been related to the ship's position with respect to the current. At depth, the background stratification was weak near $5 \times 10^{-7} \mathrm{~s}^{-2}$. Over the first $9 \mathrm{~h}$ of the transect, elevated bands of $N^{2} \sim 10^{-4.5} \mathrm{~s}^{-2}$ were observed at depth, between roughly $40 \mathrm{~m}$ and the bottom (light blue shading in Fig. 3a). These bands appear to be at relatively wellconstrained angles with the vertical. Shear squared $S^{2}$ (Fig. 3b) and inverse Richardson number $\mathrm{Ri}^{-1} \equiv S^{2} / N^{2}$ (Fig. 3c) are roughly correlated with the bands of elevated $N^{2}$. Early in the transect, elevated $\epsilon$ (Fig. 3d) was observed both near the pycnocline and in patches near the bottom. Closer examination of the data indicates that the near-bottom patches of large $\epsilon$ (white contours in Fig. 3a) tend to be capped by bands of elevated $N^{2}$. 


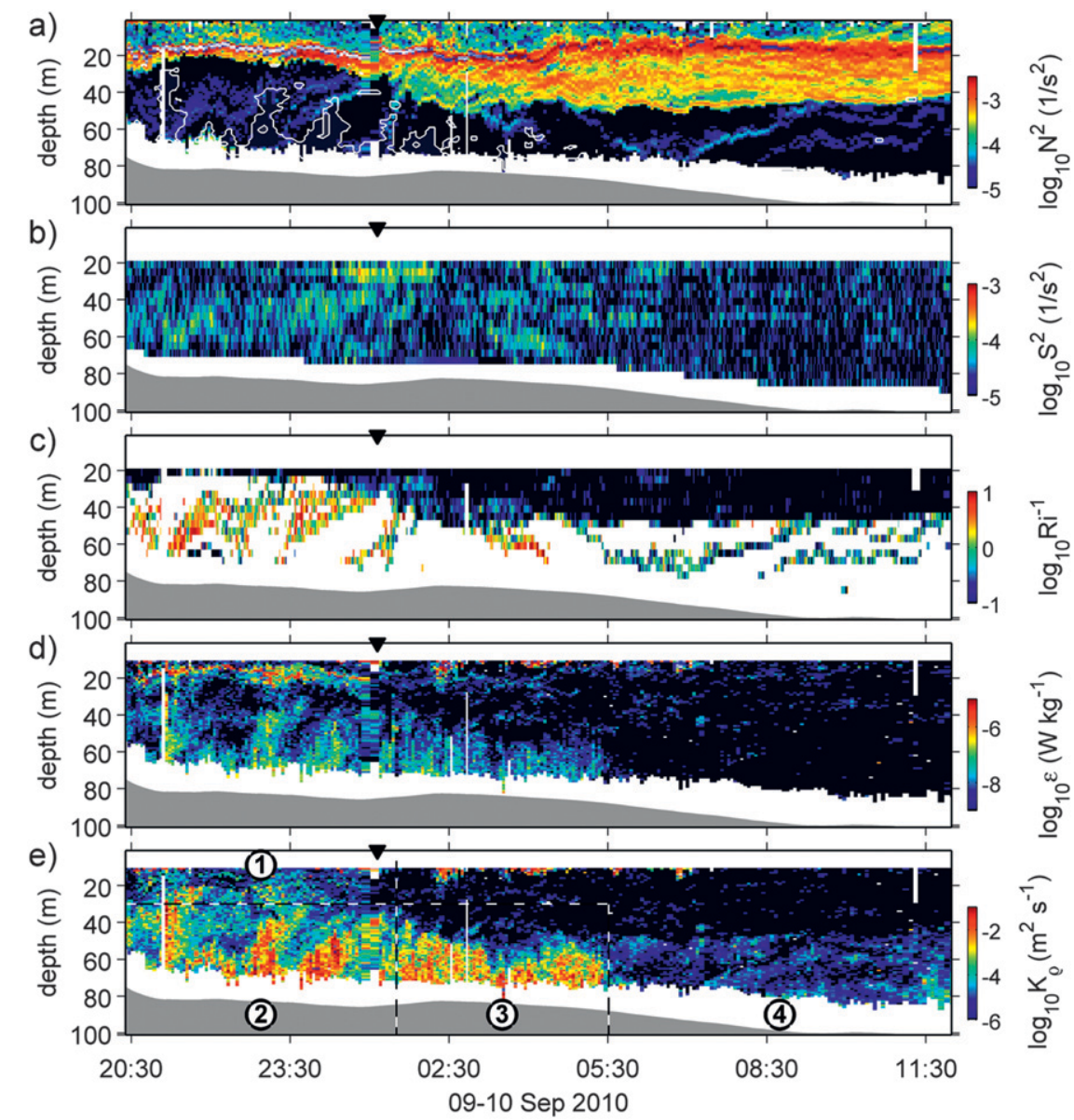

FIG. 3. (a) $\log _{10} N^{2}$, (b) $\log _{10} S^{2}$, (c) $\log _{10} \mathrm{Ri}^{-1}$, (d) $\log _{10} \epsilon$, and (e) $\log _{10} K_{\rho}$ along the microstructure transect. Black markers near the top of the panels indicate the time when the ship turned toward the northeast. White contours in (a) show regions where $\epsilon>10^{-7.5} \mathrm{~W} \mathrm{~kg}^{-1}$ at depths greater than $25 \mathrm{~m}$. Here, $\mathrm{Ri}^{-1}$ is only plotted for $N^{2}>10^{-5}$. Dashed lines in (e) divide the transect qualitatively into four regions.

The $K_{\rho}$ (Fig. 3e) is largest near the bottom, where high $\epsilon$ and weak $N^{2}$ occur. Both $\epsilon$ and $K_{\rho}$ are small in the latter portion of the transect, where the ship was located on the periphery of the energetic current.

The transect was divided into four regions, qualitatively based on the character of the measured current and mixing. Regions 1 and 2 occupy the upper portion of the transect and were confined primarily to sampling down the side channel at the head of the canyon. Region 1 encompasses mixing near the pycnocline, and region 2 encompasses mixing located at depth. Regions 3 and 4 occupy the latter portion of the transect outside the region of strong flow. Region 3 includes the area beneath the pycnocline where relatively strong mixing was observed. Region 4 encompasses all other data, including those above region 3. This division will be utilized for discussion purposes (section 4 ).

\section{Discussion}

Mean and median values of $\epsilon$ and $K_{\rho}$ are given in Table 1 . Values are calculated by disregarding samples with $\sigma<23.85 \mathrm{~kg} \mathrm{~m}^{-3}$. This criterion effectively eliminates large values of $K_{\rho}$ in isolated patches near the surface of region 4 (apparent in Figs. 3d,e above $\sim 15-\mathrm{m}$ depth) but does not influence mean values in other

TABLE 1. Mean and median values of $\epsilon$ and $K_{\rho}$.

\begin{tabular}{ccc}
\hline \hline Region & $\begin{array}{c}\epsilon\left(\mathrm{W} \mathrm{kg}^{-1}\right) \\
\text { Mean }(\text { median })\end{array}$ & $\begin{array}{c}K_{\rho}\left(\mathrm{m}^{2} \mathrm{~s}^{-1}\right) \\
\text { Mean }(\text { median })\end{array}$ \\
\hline 1 & $5 \times 10^{-7}\left(6 \times 10^{-9}\right)$ & $3 \times 10^{-3}\left(2 \times 10^{-5}\right)$ \\
2 & $4 \times 10^{-8}\left(7 \times 10^{-9}\right)$ & $6 \times 10^{-3}\left(3 \times 10^{-4}\right)$ \\
3 & $1 \times 10^{-8}\left(2 \times 10^{-9}\right)$ & $3 \times 10^{-3}\left(2 \times 10^{-5}\right)$ \\
4 & $4 \times 10^{-9}\left(1 \times 10^{-10}\right)$ & $2 \times 10^{-5}\left(4 \times 10^{-7}\right)$ \\
\hline
\end{tabular}


regions. Because these patches are linked to the surface, they are disregarded.

Even though the largest values of $\epsilon$ are found in region 1 $\left(\sim 1 \times 10^{-4} \mathrm{~W} \mathrm{~kg}^{-1}\right.$, with a mean value more than an order of magnitude larger than other regions), the largest estimates of $K_{\rho}$ are associated with region 2 because of low $N^{2}$ found there. Note that the median value of $K_{\rho}$ in region $2\left(3 \times 10^{-4} \mathrm{~m}^{2} \mathrm{~s}^{-1}\right)$ is an order of magnitude greater than the median values in regions 1 and $3(2 \times$ $10^{-5} \mathrm{~m}^{2} \mathrm{~s}^{-1}$ ) and almost three orders of magnitude larger than that observed in region $4\left(4 \times 10^{-7} \mathrm{~m}^{2} \mathrm{~s}^{-1}\right)$, which is characterized by extremely low $\epsilon$ and $K_{\rho}$. In fact, the median value of $\epsilon$ in region 4 is at the noise floor of the VMP. The $\epsilon$ and $K_{\rho}$ are intermediate in regions 1 and 3, with the mean and median values falling between those of regions 2 and 4.

\section{a. Dynamics influencing mixing}

Elevated $\epsilon$ in region 1 is assumed to be associated with shear instability in the current; this assertion, however, is difficult to assess directly because the first ADCP velocity bin is located at 20-m depth and high $\epsilon$ occurs mostly above this depth. Also, the available vertical bin size for ADCP data (4 m) is too coarse to adequately resolve the shear. It is unlikely that mixing is directly related to surface processes (e.g., convection, surface wave breaking, ship wake, etc.), as a region of reduced $\epsilon$ at $\sim 12$-m depth separates the region of elevated $\epsilon$ from the surface. In regions 2 and 3, elevated $\epsilon$ is primarily confined between the bottom and bands of elevated $N^{2}$ (white contours in Fig. 3a). The possibility that mixing in these two regions may be associated with near-inertial wave activity is discussed below. The lack of mixing in region 4 is possibly attributed to the fact that the transect was located outside the core of the coastal current in a low-energy environment.

For internal waves, the slope of the wavenumber vector $\alpha$ is related to the wave frequency $\omega, N^{2}$, and the Coriolis frequency $f$ by

$$
\alpha^{2}=\frac{\omega^{2}-f^{2}}{N^{2}-\omega^{2}} .
$$

Converting the transect into spatial coordinates using the latitude and longitude, the slope of $N^{2}$ bands can be directly estimated as $\alpha \approx \pm 0.008$. (Although of both signs, the slope magnitude is similar throughout the transect.) Using the above relationship and the observed $N=4.2 \times 10^{-3} \mathrm{~s}^{-1}$ (corresponding to the stratification inside elevated bands) and $f=1.38 \times 10^{-4} \mathrm{~s}^{-1}$, the frequency of internal waves with this characteristic slope is roughly $1.42 \times 10^{-4} \mathrm{~s}^{-1}$, slightly greater than the inertial frequency.

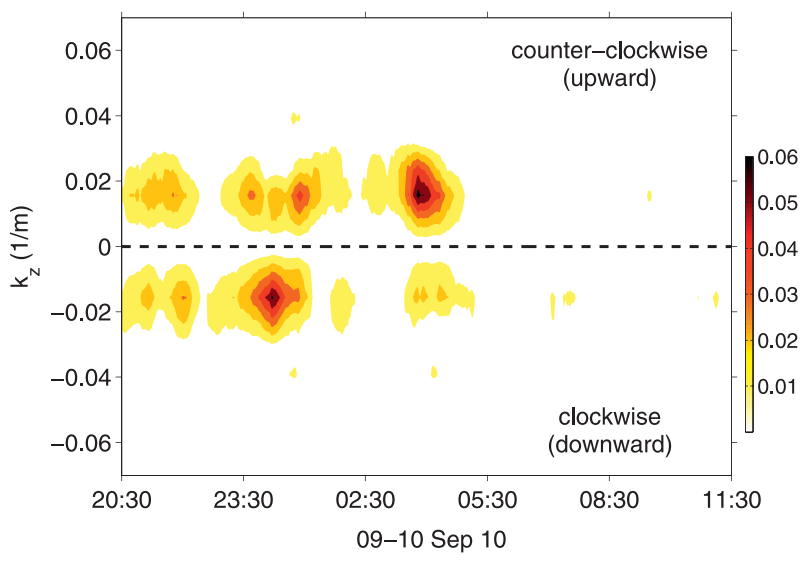

FIG. 4. Rotary spectra of perturbation velocity fields $\left(u^{\prime} / v^{\prime}\right)$. Spectra were calculated for depths greater than $25 \mathrm{~m}$ at each ADCP time bin (i.e., every minute), before a 10 -point (10 min) running average was applied. Spectra have been normalized so that integrated spectral density is equal to the velocity variance.

The characteristic slope of these bands may be set by internal wave strain and shear fields. Rotary spectra of the velocity (Fig. 4) indicate that region 2 is dominated by downward energy propagation (particularly in the latter portion of region 2) and region 3 by upward propagation, consistent with the tendency of slopes of $N^{2}$ bands to be of opposite signs in these two regions. The top of the bottom boundary layer is presumably given by bands of elevated stratification and, as stated previously, these stratification bands tend to cap regions of strong mixing. Whether internal wave-induced shear contributes to elevated mixing is not clear (i.e., internal wave activity could simply act to modify the shape of the bottom boundary layer). However, considering the tendency for both upward and downward propagation in velocity as well as the value estimated for $\omega$, it seems probably that the structures (if not the magnitudes) of $\epsilon$ and $K_{\rho}$ are associated with nearinertial wave activity.

Note that $\omega$ is also close to the $M_{2}$ tidal frequency; however, tidal forcing is extremely weak in this area (e.g., Padman and Erofeeva 2004; Woodgate et al. 2005), suggesting the signal may instead be attributed to wind forcing. Previous observations beneath the pack ice indicate that internal wave energy levels in the Arctic are considerably weaker than those in lower latitudes (Levine et al. 1985; Plueddemann 1992; Pinkel 2005). This tendency has been attributed to the presence of sea ice, which dampens the transfer of momentum from the atmosphere to the ocean and dissipates reflected internal waves within the ice-ocean boundary layer (Morison et al. 1985; Pinkel 2005). It follows that, if the mixing observed here is due to 

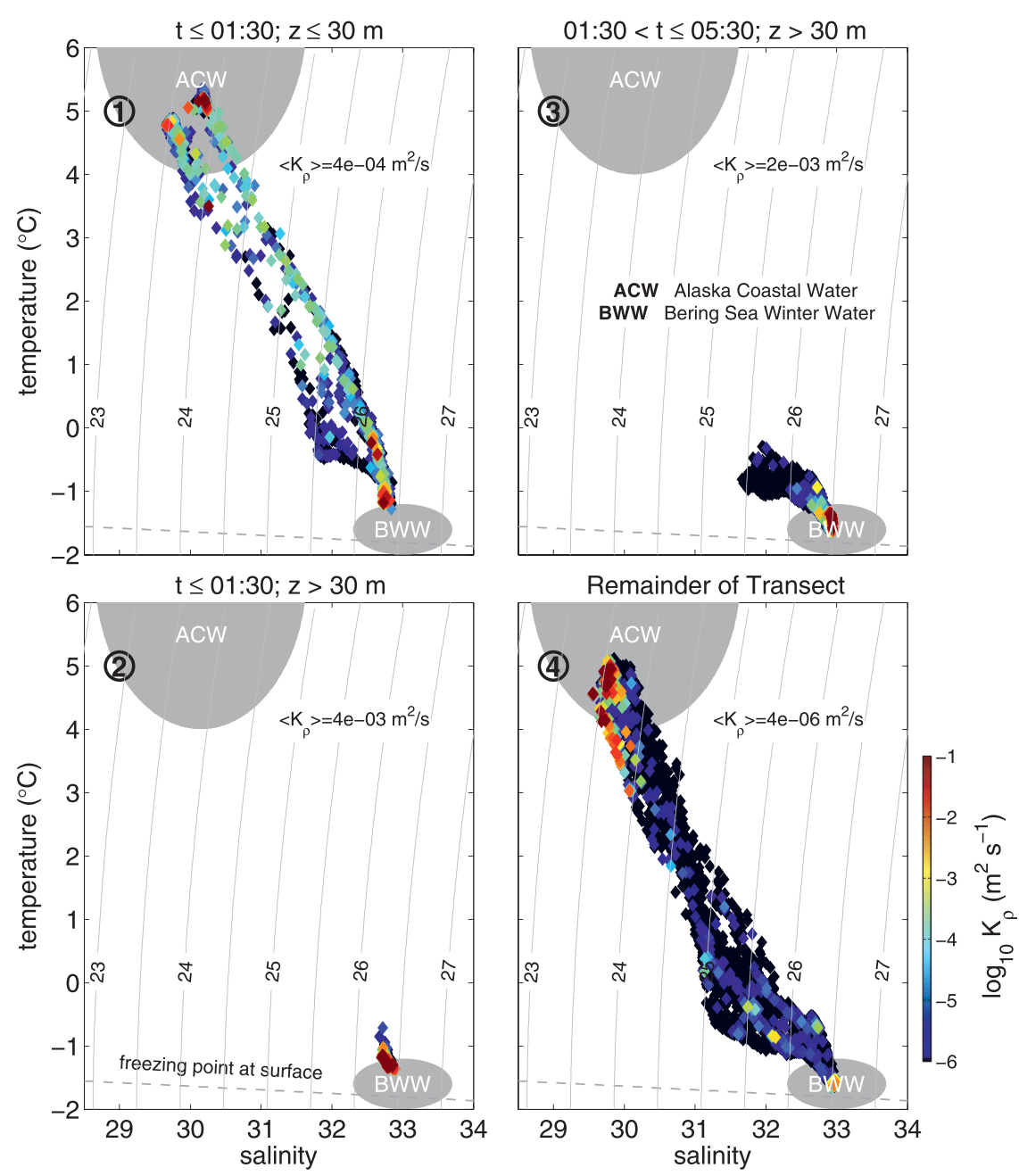

FIG. 5. $T-S$ plots for regions $1-4$ mapped in Fig. 3e. Color of points indicates the $\log _{10} K_{\rho}$. Mean values (excluding the upper/lower $5 \%$ ) of $K_{\rho}$ are given for measurements with $\sigma>23.85 \mathrm{~kg} \mathrm{~m}^{-3}$. Data were reordered so that the largest values of $K_{\rho}$ appear at the top of the scatterplot.

enhanced internal wave shear, seasonality associated with ice cover and consequent near-inertial wave activity may be important.

\section{b. Consequences of mixing}

Mixing between ACW and BWW occurs in region 1 , where $N^{2}$ is large and the mean value of $K_{\rho}$ is elevated two orders of magnitude over that of region 4 (Fig. 5). High values of $K_{\rho}$ in regions 2 and 3 are not effective in mixing across isopycnals, as data are confined to a very small region in $T-S$ space. This is especially true in region 2 , in which temperature and salinity vary by only $0.65^{\circ} \mathrm{C}$ and 0.22 salinity units. Although mixing in these regions cannot greatly influence $T-S$ properties, it may be of consequence for nutrient cycling near the bottom boundary layer and thus possibly important to the benthic community.
Apart from a patches located near the surface $(\sigma<$ $23.85 \mathrm{~kg} \mathrm{~m}^{-3}$ ) most values of $K_{\rho}$ are extremely weak in region 4 , so that despite containing data that span across $T-S$ space little mixing between $\mathrm{ACW}$ and BWW occurs here. (Note that the mean values of $K_{\rho}$ given in Table 1 differ from those in Fig. 5, because the former gives the mean of all data and the latter excludes the highest/lowest $5 \%$.)

To establish an estimate on the potential of mixing to modify $T-S$ properties about the pycnocline within regions 1 and 2, the vertical divergence of temperature and salt flux can be calculated as

$$
\frac{\partial}{\partial z} J_{(\cdot)}=\frac{\partial}{\partial z} K_{\rho} \frac{\partial}{\partial z}(\cdot)
$$

Average profiles (Figs. 6a-d) were created by remapping variables $\left(\epsilon, N^{2}, K_{\rho}, T, S, J_{T}, J_{S}\right.$, and depth) so that the 

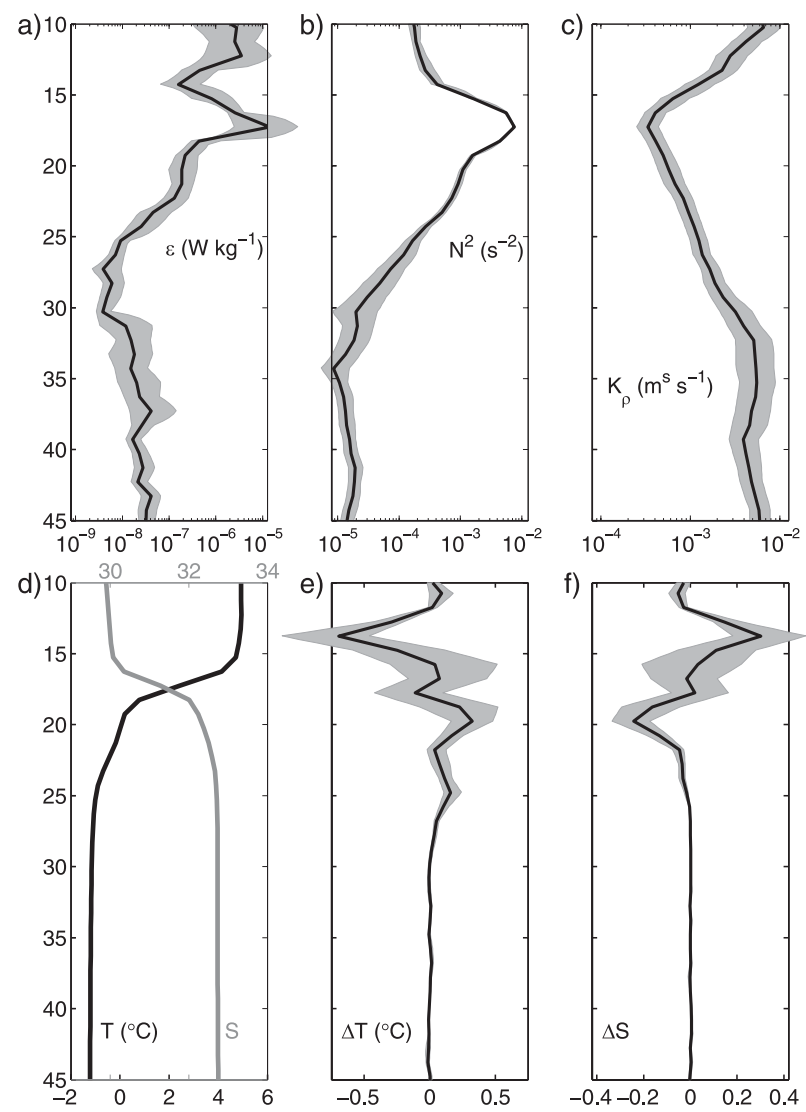

FIG. 6. Profiles of (a) $\epsilon$, (b) $N^{2}$, (c) $K_{\rho}$, and (d) $T$ and $S$ averaged over regions 1 and 2. Corresponding estimates of (e) $\Delta T$ and (f) $\Delta S$ attributed to vertical mixing over one hour. Gray bounds are set by the $90 \%$ bootstrap confidence limits on mean values.

thermoclines/haloclines are aligned before averaging across regions 1 and 2. This process is similar to mapping onto density coordinates. The $90 \%$ confidence limits (gray shading in Fig. 6) are set by the bootstrap on the mean.

The $\epsilon$ tends to a local maximum at the depth of maximum stratification (Figs. 6a,b). The vertical structure of $K_{\rho}$ mimics the inverse of $N^{2}$ with a minimum located near the pycnocline. At depth, weak stratification results in extremely large values of $K_{\rho}$. Note that beneath the pycnocline calculation of a mixing diffusivity from the mean values of $\epsilon$ and $N^{2}$ would yield a much smaller value than that produced by calculating $K_{\rho}$ prior to averaging. For example, $0.2(3 \times$ $10^{-8} \mathrm{~W} \mathrm{~kg}^{-1} / 1 \times 10^{-5} \mathrm{~s}^{2}$ ) is roughly $6 \times 10^{-4} \mathrm{~m}^{2} \mathrm{~s}^{-1}$ as opposed to $\sim 4 \times 10^{-3} \mathrm{~m}^{2} \mathrm{~s}^{-1}$. This attribute is not true at or above the pycnocline, where mean values of $\epsilon$ and $N^{2}$ reproduce the character of the mean $K_{\rho}$ reasonably well.

The change in $T$ and $S$ by vertical mixing over the course of $\Delta t=1 \mathrm{~h}$ (selected as an arbitrary time scale) was estimated from

$$
\frac{\partial(\cdot)}{\partial t}=\frac{\partial}{\partial z} J_{(\cdot)} \rightarrow \Delta(\cdot)=\frac{\partial}{\partial z} J_{(\cdot)} \times \Delta t
$$

Profiles of $\Delta T$ and $\Delta S$ calculated in this manner are shown in Figs. 6e,f. The resultant changes in $T$ and $S$ are confined to within $\sim 7 \mathrm{~m}$ of the pycnocline. Over the course of one hour, water just above the pycnocline cools by roughly $0.6^{\circ} \mathrm{C}$ and water just below the pycnocline warms by $0.3^{\circ} \mathrm{C}$. Water increases in salinity by +0.3 above the pycnocline and decreases by -0.2 below the pycnocline. Values represent calculations using the mean $J_{T}$ and $J_{S}$. Because 1) the advective time scale for a parcel of water to travel across region 1 (13 km at $0.5 \mathrm{~m} \mathrm{~s}^{-1}$ ) is roughly $7 \mathrm{~h}$ and 2) high mixing near the pycnocline may have continued past region 1 if the ship stayed within the energetic current, the use of $\Delta t=1 \mathrm{~h}$ may provide a conservative estimate.

The above approximation assumes that a water parcel follows the transect line or at least is influenced by vertical mixing with the same distribution as that measured along the transect. Because the current direction is aligned with the transect path over regions 1 and 2, this approximation may be reasonable. Regardless, given the large values of $K_{\rho}$, diapycnal mixing near the pycnocline may be important to the evolution of water mass properties in Barrow Canyon.

\section{Conclusions}

Observations from a microstructure transect acquired down the head of Barrow Canyon are described in detail. The first part of the transect was made through relatively high $\left(0.5 \mathrm{~m} \mathrm{~s}^{-1}\right)$ down-canyon flow; elevated values of turbulent mixing were observed both in the interior and near the bottom over this region. In contrast, the latter part of the transect, which was located outside the core of the current, was quiescent with very little mixing. Elevated mixing in the interior of the water column is assumed to be associated with shear instability in the current; however, this assumption is based on the fact that elevated mixing is clearly isolated from the surface by a band of low dissipation rather than other supporting evidence (e.g., low Ri number). Mixing near the bottom is primarily confined within bands of increased stratification with slopes parallel to near-inertial internal wave rays; therefore, either the turbulence itself or its structure (i.e., size/shape of turbulent patches) may be influenced by wave activity.

Regardless of the mechanism, these data suggest that significant mixing between water masses, in particular the summer-formed ACW and winter-formed BWW, may occur in the canyon. Water mass transformation 
that occurs in Barrow Canyon may be of importance to heat storage and ventilation in the deep Arctic, given linkages between the shelf and basin that exist in this region. By proxy, such mixing may also be important for nutrient exchange between the relatively nutrientpoor summer water and nutrient-rich winter water. Although elevated mixing near the bottom will not influence $T-S$ properties and density, it may be important to nutrient cycling within the bottom boundary layer. This result is of interest because, within the Chukchi Sea, Barrow Canon stands out as a hotspot of biological activity with a strong benthic component (Grebmeier et al. 2006).

As with previous observations from the Arctic (D'Asaro and Morison 1992; Sundfjord et al. 2008; Rainville and Winsor 2008), these results indicate that elevated mixing may be associated with regions of complex topography and in shallow areas. The elevated mixing rates noted here are also consistent with previous work that find an increase in internal wave energy and TKE dissipation within canyons at lower latitudes (e.g., Gordan and Marshall 1976; Carter and Gregg 2002; Thurnherr et al. 2005; Lee et al. 2009). However, it is important to consider that, despite the shallow, topographically complex environment, very low values of mixing were also observed here. The spatial patchiness of mixing within Barrow Canyon may be attributed to some combination of the spatial variability of the energetic mean flow and the complexities of an internal wave field constrained by the canyon geometry. More (high resolution) data are needed to examine the detailed character of the internal wave field in Barrow Canyon, and future studies may provide a useful contrast to other canyons, in which wave dynamics appear to be dominated by tidal activity (e.g., Hotchkiss and Wunsch 1982; Kunze et al. 2002; Lee et al. 2009).

Acknowledgments. I would like to thank J. Farrar for loaning the VMP-2000 for use during this experiment and R. Pickart for providing the ship time and ADCP data. Thank you also to S. Roberts for providing the multibeam data. A. Plueddeman, J. Lord, S. Whelan, and B. Pietro provided logistical support before and after the cruise. I acknowledge L. St. Laurent and K. Decoteau for providing information regarding technical operation of the VMP and processing details. J. Kemp and F. Bahr helped ensure successful setup and operation of the equipment while at sea. In addition, I thank the Captain and Crew of the USGS Healy as well as many scientific staff who helped stand watch during measurements. ELS was supported as a WHOI Postdoctoral Scholar through the WHOI Ocean and Climate Change Institute.

\section{REFERENCES}

Aagaard, K., and A. T. Roach, 1990: Arctic ocean-shelf exchange: Measurements in Barrow Canyon. J. Geophys. Res., 95, $18163-18175$.

— L. K. Coachman, and E. Carmack, 1981: On the halocline of the Arctic Ocean. Deep-Sea Res., 28A, 529-545.

Allen, S. E., and X. Durrieu de Madron, 2009: A review of the role of submarine canyons in deep-ocean exchange with the shelf. Ocean Sci., 5, 607-620, doi:10.5194/os-5-607-2009.

Carter, G. S., and M. C. Gregg, 2002: Intense, variable mixing near the head of Monterey Submarine Canyon. J. Phys. Oceanogr., 32, 3145-3165.

Coachman, L. K., K. Aagaard, and R. B. Tripp, 1975: Bering Strait: The Regional Physical Oceanography. University of Washington Press, $172 \mathrm{pp}$.

D'Asaro, E. A., and J. H. Morison, 1992: Internal waves and mixing in the Arctic Ocean. Deep-Sea Res., 39A, S459-S484.

Fer, I., G. Voet, K. S. Seim, B. Rudels, and K. Latarius, 2010: Intense mixing of the Faroe Bank Channel overflow. Geophys. Res. Lett., 37, L02604, doi:10.1029/2009GL041924.

Gordan, R. L., and N. F. Marshall, 1976: Submarine canyons: Internal wave traps? Geophys. Res. Lett., 3, 622-624.

Grebmeier, J. M., L. W. Cooper, H. M. Feder, and B. I. Sirenko, 2006: Ecosystem dynamics of the Pacific-influenced northern Bering and Chukchi Seas in the Amerasian Arctic. Prog. Oceanogr., 71, 331-361, doi:10.1016/j.pocean.2006.10.001.

Hotchkiss, F. S., and C. Wunsch, 1982: Internal waves in Hudson Canyon with possible geological implications. Deep-Sea Res., 29, 415-442.

Kunze, E., L. K. Rosenfeld, G. S. Carter, and M. C. Gregg, 2002: Internal waves in Monterey Submarine Canyon. J. Phys. Oceanogr., 32, 1890-1913.

Lee, I.-H., R.-C. Lien, J. T. Liu, and W.-s. Chuang, 2009: Turbulent mixing and internal tides in Gaoping (Kaoping) Submarine Canyon, Taiwan. J. Mar. Syst., 76, 383-396.

Lenn, Y. D., and Coauthors, 2009: Vertical mixing at intermediate depths in the Arctic boundary current. Geophys. Res. Lett., 36, L05601, doi:10.1029/2008GL036792.

Levine, M. D., C. A. Paulson, and J. H. Morison, 1985: Internal waves in the Arctic Ocean: Comparison with lower latitude observations. J. Phys. Oceanogr., 15, 800-809.

Lueck, R., F. Wolk, and H. Yamazaki, 2002: Oceanic velocity microstructure measurements in the 20th century. J. Oceanogr., 58, 153-174.

Morison, J. H., C. E. Long, and M. D. Levine, 1985: Internal wave dissipation under sea ice. J. Geophys. Res., 90 (C6), 11959 11966.

Moum, J. N., M. C. Gregg, R. C. Lien, and M. E. Carr, 1995: Comparison of turbulence kinetic energy dissipation rate estimates from two ocean microstructure profilers. J. Atmos. Oceanic Technol., 12, 346-366.

Osborn, T. R., 1980: Estimates of the local rate of vertical diffusion from dissipation measurements. J. Phys. Oceanogr., 10, 83-89.

Padman, L., and T. M. Dillon, 1991: Turbulent mixing near the Yermak Plateau during the Coordinated Eastern Arctic Experiment. J. Geophys. Res., 96, 4769-4782.

— for the Arctic Ocean. Geophys. Res. Lett., 31, L02303, doi:10.1029/2003GL019003.

Pickart, R. S., T. J. Weingartner, L. J. Pratt, S. Zimmermann, and D. J. Torres, 2005: Flow of winter-transformed Pacific water 
into the western Arctic. Deep-Sea Res., 52, 3175-3198, doi:10.1016/j.dsr2.2005.10.009.

Pinkel, R., 2005: Near-inertial wave propagation in the western Arctic. J. Phys. Oceanogr., 35, 645-665.

Plueddemann, A. J., 1992: Internal wave observations from the Arctic Environmental Drifting Buoy. J. Geophys. Res., 97 (C8), 12 619-12 638.

Rainville, L., and P. Winsor, 2008: Mixing across the arctic ocean: Microstructure observations during the Beringia 2005 expedition. Geophys. Res. Lett., 35, doi:10.1029/2008GL033532.

Signorini, S. R., A. Münchow, and D. Haidvogel, 1997: Flow dynamics of a wide Arctic canyon. J. Geophys. Res., 102, 18 661-18 680.

Spall, M. A., 2007: Circulation and water mass transformation in a model of the Chukchi Sea. J. Geophys. Res., 112, C05025, doi:10.1029/2005JC003364.

Sundfjord, A., I. Ellingsen, D. Slagstad, and H. Svendsen, 2008: Vertical mixing in the marginal ice zone of the northern Barents Sea-Results from numerical model experiments. Deep-Sea Res. II, 55 (20-21), 2154-2168.

Thurnherr, A. M., L. C. St. Laurent, K. G. Speer, J. M. Toole, and J. R. Ledwell, 2005: Mixing associated with sills in a canyon on the midocean ridge flank. J. Phys. Oceanogr., 35, 13701381.

Toole, J., R. Krishfield, M.-L. Timmermans, and A. Proshutinsky, 2011: The Ice-Tethered Profiler: Argo of the Arctic. Oceanography, 24, 126-135.
Walsh, J. J., and Coauthors, 1989: Carbon and nitrogen cycling within the Bering/Chukchi seas: Source regions for organic matter effecting AOU demands of the Arctic Ocean. Prog. Oceanogr., 22, 277-359, doi:10.1016/0079-6611(89)90006-2.

Watanabe, E., 2011: Beaufort shelf break eddies and shelf-basin exchange of Pacific summer water in the western Arctic Ocean detected by satellite and modeling analyses. J. Geophys. Res., 116, C08034, doi:10.1029/2010JC006259.

Weingartner, T. J., D. J. Cavalieri, K. Aagaard, and Y. Sasaki, 1998: Circulation, dense water formation, and outflow on the northeast Chukchi shelf. J. Geophys. Res., 103, 7647-7662.

_ , K. Aagaard, R. Woodgate, S. Danielson, Y. Sasakic, and D. Cavalieri, 2005: Circulation on the north central Chukchi Sea shelf. Deep-Sea Res., 52, 3150-3174.

_ - S. L. Danielson, J. L. Kasper, and S. R. Okkonen, 2009: Circulation and water property variations in the nearshore Alaska Beaufort Sea. U.S. Department of Interior Minerals Management Service Tech. Rep. M03PC00015, 103 pp.

Winsor, P., and D. C. Chapman, 2004: Pathways of Pacific water across the Chukchi Sea: A numerical model study. J. Geophys. Res., 109, C03002, doi:10.1029/2003JC001962.

Woodgate, R. A., and K. Aagaard, 2005: Revising the Bering Strait freshwater flux into the Arctic Ocean. Geophys. Res. Lett., 32, L02602, doi:10.1029/2004GL021747.

$\longrightarrow,-$, and T. J. Weingartner, 2005: A year in the physical oceanography of the Chukchi Sea: Moored measurements from autumn 1990-1991. Deep-Sea Res. II, 52, 3116-3149, doi:10.1016/j.dsr2.2005.10.016. 